\title{
Transparency and Spending Review: A Model for Italian Healthcare
}

\author{
Paola Adinolfi ${ }^{*}$
}

\begin{abstract}
Transparency and spending review are two key items in the public policies of most Western countries. Though they are constantly perceived as targets to be pursued, little evidence is found of an approach that may synergistically combine such two issues with a view to producing value. The T.R.E.E. project is an example of an integrated approach to the change management process that connects change to the production of value, as well as to training, organisation and communication.
\end{abstract}

Keywords: Transparency; Change Management; Spending Review; Italian Healthcare, Global Markets

\section{The Disruptive Scope of Transparency}

Transparency is more and more of a hot, relevant issue after the enactment of the new legislation under which public sector organisations are bound to disclose information to prevent corruption, the defeat of which is no longer left to criminal proceedings only. Transparency actually also involves for-profit organisation since one of its main drivers is technological advancement: that's why now we can see farther and faster, at a lower cost and more easily than ever, and we can be seen, and other people can see what we see, and we all can see what other people see, in a recursive mirror-like effect that resembles an Escher painting. Often, transparency goes hand in hand with spending review, another key issue in the public policies of the Western countries, both perceived as goals to be pursued, though there is little evidence - both in the literature and in practice - of an approach that may help synergistically combine such two issues with a view to producing value. This paper proposes a conceptual framework for transparency and spending review - set in the context of healthcare. Inspired by a change management process proposed to some healthcare facilities in Campania (Southern Italy), this paper suggests a systemic change model, designed to promote synergisms between transparency and rational management and make them serve the ultimate purpose of producing value in healthcare.

The impact of transparency on organisations is disruptive. Any organisation, from for-profit corporations to non-profit organisations, from banks, to public sector organisations, have evolved over time to thrive in an opaque environment, where most knowledge had a local character, it was fairly easy to keep key information

*Full Professor of Organization Studies, University of Salerno (padinolfi@unisa.it) 
confidential, and people were, if not blind, short-sighted (Gorodnichenko \& Peter, 2007; Barth, Lin, Lin, \& Song, 2009; Themudo, 2014). When such organisations found themselves - suddenly - thrown in daylight, they inevitably had to change to respond to the new transparency; if they had not, they would have died out (Salvioni, 2002; Codignola, 2003).

We can learn something about the future of organisations from primordial oceans. The organisational revolution triggered by increasing information transparency looks surprisingly similar to the biological revolution that was started over half a billion years ago by a change in the chemistry of the oceans and the atmosphere, which turned all things muddy into something transparent: this is that spectacular burst of innovation known as "Cambrian explosion", so that, in a geological instant of several million years, the organisms developed new organs, new body shapes and new offensive and defensive strategies (Valentine, Jablonski, \& Erwin, 1999).

According to the most authoritative assumption, such evolution was triggered by transparency (Hameroff, 1998). Until then, any perception had been a matter of proximity, by contact or pressure waves. Instead, in daylight, predators could follow their prey from a distance and engage in offensive strategies; while preys could see predators coming and engage in defensive strategies. The outer parts of the body (visual organs, limbs, claws, toothed jaws and bodily defences) were the first to come out in the evolutionary process, as did the nervous system, which made new offensive and defensive behaviours possible: camouflaging, alarm calls to alert about impending danger, bright patterns and colours to look deceptively poisonous, use of faeces or dead animals as deceptive signs of a prey to confuse predators, or spraying ink to lead predators astray.

Interestingly, such evolution has some points in common with the transition that organisations are going through in response to an increasing demand for transparency. The result of such phenomenon was actually a progressive adaptation of the outer parts of the body (above all: public relation offices, marketing areas and legal staff) in terms of getting bigger and more capable to easily and readily respond to increasing environmental changes (Raisch \& Birkinshaw, 2008; Brondoni, 2016). Likewise, a rising need for transparency has boosted the development of corporate nervous systems: think for instance of corporate intelligence, which uses new offensive and defensive strategies in information warfare (Kruse, Frederick, Jacobson, \& Monticone, 2017). Offensive strategies include, for instance, campaigns to promote corporate reputation or to discredit that of detractors, or preventive offence; defensive strategies are comparable to those used in aerial warfare, where "chaff", i.e. clouds of small metal fragments that attract missiles, is used: corporations use "chaff" made of megabytes of disinformation to distract their competitors.

The rate at which transparency tends to change organisations depends on the competitive niche. Businesses are those most exposed to competitive pressure and so they are also the most vulnerable to transparency, because their customers can quickly go for a competitor's offer; actually, a decade-long brand can collapse in a moment unless it effectively adapts and responds to the customers' negative feedback. Therefore, such companies have very quickly evolved in response to an increasing need for transparency.

Even in the public sector an increasing demand for transparency, as well as the progress made in big data analytics and in data access and viewing techniques, tend 
to trigger powerful cycles of feedback, which further boost the demand for transparency (Janssen et al., 2017). There are limits, however, on an organisation's adaptive potential: in many public sector areas, the lawmaker thoroughly defines the organisational framework and the board members. If, on one hand, this may be beneficial as tasks and roles are all the same all over the country, on the other hand this slows down the organisation's adaptation to the new external environment, as it depends on the length of the institutional reform, and reduces the chance to find organisational solutions that may promptly respond to specific circumstances. Other factors that reduce such adaptive skills are the organisation's features: a "functional" form of organisational structure, overly mechanical and procedural integrative mechanisms, no third-party recipients, i.e. no structural factors to sense signals from the external environment.

All this reduces and slows down the public sector's ability to benefit from transparency by adapting to it, so as to use it to increase the production of value for the public.

\section{The Limits of Transparency}

Sunlight is said to be the most effective disinfectant (Acra et al., 1989). This is true, both literally and metaphorically. However, too much sunlight can also be harmful, not only literally but also metaphorically: exposing too much of an organisation's own operational mechanisms is a cost and it is also a risk, because it may impair its effectiveness (Strang \& Macy, 2001).

One of the key tenets of game theory is that agents need to keep some "secrets". An agent who reveals a secret to a third party will lose some useful independence and might be manipulated (Hellwig, 2002). Of course, such argument is particularly relevant when applied to a company's strategic assets, such as industrial development plans, production strategies and models, or other proprietary information (Schlegelmilch, Ambos, \& Chini, 2003). Conversely, transparency about the production of value (without going into the details of the way it is produced) does not seem to expose a company to any special risk. What about the public sector? It has to adhere to Legislative Decree no. 33 of March $14^{\text {th }} 2013$, which redesigns the legislation on public access rights and compulsory disclosure, transparency and provision of information by public sector organisations. Do citizens have any practical advantage from all the information that must be disclosed under the Decree? Of course, not: no one would log into the website of a public authority to get the information that must be disclosed under the Decree; one does, instead, if one needs to use some service: just look, for example, at data about access to the website of the National Institute of Social Security (INPS): it is visited by about 800 thousand people a day, while the Transparent Administration section is visited 11,500 times a month (Lenk, 2002). The requirements that public sector organisations have to fulfil risk, instead, to verge on gossiping about the income of this or that manager, thus also endangering privacy.

In the light of such considerations, the problem is to strike the right balance between transparency and confidentiality. Well, if we consider that the effect of transparency is attracting attention and getting focalisation, then it is useful to make important things, such as the production of value, transparent. Making the value 
produced by an organisation and its processes transparent fulfils the very scope of transparency: the organisation's performance, and which processes are performing well and which ones are not, would be easily understood.

In the business world, there are instantly intelligible indicators, such as profit or the number of customers, which are sound indicators to assess the production of value. In the public sector world, where in the provision of services the market exchange mechanism is missing, indicators can be ambiguously understood: for instance, a municipality's financial deficit can mean that it is underfunded; a drop in the number of users of a local health unit may mean that preventive medicine has been successful. Because of such ambiguity, some poorly-performing situations, may last a long time.

In addition, the fact that resources come from public funds instead of market exchanges pushes the goal of economic breakeven into the background (so that, at best, it becomes just a requirement), with the consequence that the public sector organisation feels no responsibility for the provision of the service and focuses on getting all the possible resources. This pushes the organisation to pursue the interests of all those players (inside and outside the organisation) that can somehow affect the chance to receive the resources. Hence the pursuit of short-term, visible goals: doctors' growing clinical autonomy, political leaders' attempting at reaching the widest consensus and so on. In this scenario, the ability to measure the production of value and make it transparent becomes crucial, since it makes up for the lack of market control. Indeed, compulsory transparency in the public sector involves the disclosure of a fairly long list of detailed information, but not the value produced by the organisation or by its sub-processes (Bisio, 2006). The legislation requires organizations, for instance, to show the price paid for buying each factor of production, whether for human resources or for those resources that are instrumental to the production of goods and/or the provision of services, but not the value that emerges from the interaction of such factors in a productive combination (Moullin, 2017). This has remarkable consequences: the fact that only specific information is disclosed drives the organisation to focus its attention on the costs that will become public and to minimise such costs, regardless of the effect it can have on the overall value. This is pushed into the background, but it is actually the real purpose to be pursued. By losing sight of value, an orientation to procedure is stimulated.

As aptly pointed out by Sabino Cassese in the $30^{\text {th }}$ October issue of Corriere della Sera, from being a liability for failing to achieve mandatory results, management liability turns into a liability for breaching procedural obligations. Most of the rules are dictated by a culture of suspicion and are designed for prevention, while the prerequisite of a free government is repression, not prevention. A manager is liable if he does not disclose information about an administrative procedure, if he does not draw up an anticorruption plan, if he does not disclose the forms and sheets needed to file procedures, if he fails to send documents by certified email to a public sector organisation, if he does not disclose the information listed in the «Transparent Administration» section and if he does not adopt the three-year transparency and integrity plan, if he does not notify the information required to complete or update the list of public sector organisations' addresses, and so on.

Such procedural responsibilities fall on the shoulders of public managers, while their leeway is shrinking, due to increasingly invasive regulations as the result of 
Parliament's inveterate habit of going into the tiniest administrative details. Add to this the requirements and inspections imposed by auditors, by the NAS (Office against the Adulteration of Foodstuffs), the Financial Police, the State Auditors' Department, the National Anticorruption Authority, and then the Regional Administrative Courts of Law, the Public Prosecutors...

Cassese's conclusion is extreme:

$\square$ If all such pressures are added up, you realise that nowadays the public sector is like a besieged fortress, with no discretionary power, that is, no choice, left. Bureaucrats are worried if not downright scared, and they'd rather take no decision at all (even more so now that the measures for the prevention of offences against public organisations seizure and expropriation - have been upgraded).

And bureaucracies are not blameless either. To administer means managing, negotiating, deciding, a complex job that requires skills and experience, that you learn less from books than «by doing». Limited or pressured in every possible way in their decision-making powers, often left out of the decision-making process, public sector organisations have adapted to lead a quiet life, to meet form and disregard substance, to wait for the word of the law or to follow the dictates of one too many watchdogs. So they have demoted themselves, have lost their technicians, while the bureaucrats are still there, they manage themselves instead of managing the State ..." (Cassese, 2017).

\section{Spending Review and Transparency in Healthcare}

A context that is set as an example and that will take centre stage in this paper, healthcare is the public-sector area in which the need for a spending review is most powerfully felt, because of a number of factors that add up to the naturally expansionistic trend of public expenditure, from the aging of the population to rampant technological advancements that produce endless technology and increasingly expensive drugs.

The traditional cost containment measures adopted in healthcare as much in Italy as in any other Western country have a direct impact on the state budget, so the most significant cost items are reduced - or capped (no increase in salaries or staff turnover, cuts and limits on expenses for goods and services, reduced investments in technology and equipment...). The underlying idea is that, by cutting a proportion of the items that have a remarkable impact on the budget and inevitably tend to expand, the deficit will decrease accordingly. This is the inspiration behind the transparency measures, which provide evidence of the cost trends of each factor of production, regardless of the way they account for the production of value.

In fact, such approach turns out to be counterproductive in terms of costs, not to mention in terms of the quality and safety of healthcare.

The first cost item that is hit by the cuts of the spending review is the staff. As it accounts for about $2 / 3$ of the healthcare budget and as public companies naturally tend to increase their staff, restrictive policies have been implemented on the medical staff as well as on the clinical support staff in all public healthcare systems. 
In a public context, where the allocation of the staff does not meet an actual need, due to the slowness and cumbersomeness of the adjustment process that is cramped by complex negotiations and regulatory procedures, linear restrictive policies applied to the staff have devastating consequences, as they affect both overstaffed and understaffed facilities.

In overstaffed facilities, such cuts, just because they are linear, can leave some excess. Such excess is not offset by investing in space and equipment that could use up the professionals' productivity; lacking a culture of assessment, the companies usually do not evaluate the cost of inactivity so they do not realise that unused space and equipment would cost much less than an unused professional (as the hourly cost of space and equipment is much lower than the hourly cost of a professional), with the consequence that the productivity of the most valuable resources - professionals - is not optimised.

In understaffed facilities, a linear cut puts too much pressure on the staff's productivity: an over-reduction of the time available for each service will inevitably reduce the quality of the service, and in healthcare this is particularly detrimental because it has consequences on safety and on patient relations, unfailingly undermining the patient's trust and increasing the chance of being sued even more frequently. In an article in the November 201 issue of the Harvard Business Review, very aptly titled "How not to cut health costs", Kaplan and Haas estimated that, with chronic liver failure, reducing the standard length of the doctor's consultation by fifteen minutes would save a mere $1 \%$ of the extra cost that would be incurred as a result of an unsuitable treatment (dialysis catheter) that a poorlycared-for patient would take, with far worse life expectancy and complications.

When they fail to respond to healthcare demand by putting pressure on the professionals' productivity, healthcare facilities tend to resort to alternative solutions, such as outsourced staff, special agreements with specialists, special agreements with their own staff, all options that are more expensive than hiring new staff. In particular, using their own staff under special agreements, as well as being much more expensive than hiring new staff, unbearably increases the professionals' workload, with negative repercussions on safety (as acknowledged by the recent European legislation on shifts).

In some countries, the support staff have been cut down, either in the outspoken (yet delusionary) attempt not to impact on patient care, or in the implicit attempt to retain those procedures that are somehow refunded (the clinical ones). Once again, savings are a vain hope, because professionals are forced to carry out administrative-bureaucratic work (which might be more inexpensively carried out by other workers), so they have less time for treating patients. A professional's time costs much more than that of the support staff, so using them for administrative work is not cost-efficient. Unleashing the professionals' energies is much more cost-efficient, so they can focus on high value-added work.

Another cost item that is affected by the financial clampdown is the purchase of goods and services: the outrageous differences in the prices paid by commissioners for their goods/services have resulted in the enforcement of several restrictive measures (the last one was Legge di Stabilità 2016). They by no means take into account the contribution that such goods and services make to the production of value. Measures such as the reduction in the number of commissioners and central purchases may make the purchasing process (a process that supports the core one, 
i.e. healthcare) more rational, but do not necessarily increase the overall production of value, unless they are part of a policy that brings in and involves all the users of such goods and services. For example, one can get a fairly good price for buying a specific type of equipment, but, if one does not take into account the combination of factors of production in which such equipment is involved and does not share it with the professionals concerned, the cost of storage or returns may rise.

What is most worrying about spending reviews, as compounded by transparency measures, is - as mentioned - that they are strictly focussed on the price of goods and services and disregard the way such goods and services are used within the overall process. To go back to Kaplan and Haas (2014), the price paid to buy bone cement remarkably varies between hospitals, but the cheapest kind of cement can be associated with a wider use of antibiotics or even of the cement itself, so it would have a greater impact on the cost of the overall process.

As said, focussing on one single factor of production would divert attention from the production of value. Even the healthcare sector, then, has not got its head around the idea that what matters - for the sake of transparency as well as for the sake of reducing costs - is to thoroughly investigate the processes, which in healthcare mainly concern treating patients in different medical conditions and finding out, partly with the help of benchmarking techniques that may actually be made easier by transparency, which kind of assets' organisation produces the highest value, with the best combination of resources, for each therapeutic procedure.

Therapeutic procedures are usually taken for granted, without being questioned, even though they can differ widely between organisations or even within the same organisation. This prevents them from finding innovative connections between previously-unrelated resources, which look underused in the light of a new mind-set that goes beyond the traditional idea of the value chain that is typical of industrial economy. In the world of public healthcare facilities, there is the lack of a complex, systemic view according to which what matters is not the intrinsic value of each asset but its place-value across the value chain that all players are involved in (not just the staff but the patients and their families too, as well as suppliers of goods and services). The straightforward, simplistic assumption that healthcare organisations provide healthcare services, companies produce goods, universities produce knowledge, and users act as "recipients" of value, has not been fully overcome yet (Palumbo, 2017 a).

This new perspective, whereby assets are judged for their place-value instead of their intrinsic value, is at the core of knowledge-based economy (Leydesdorff \& Zhou, 2014). If all the seemingly unconnected players (and assets) that revolve around a therapeutic procedure take a mutually synergistic place, despite retaining their specific expertise, they would create an integrated value creation system.

\section{The T.R.E.E. Project}

Despite increasing awareness of cost containment and healthcare risks, no solutions have been provided that can deal with such problem in an integrated way. The available options are mainly based on consultancy and merely involve training staff on costs, risks and quality, economic analyses for increasing the value of 
services based on Diagnosis-Related Groups, process certification confined to graphic modelling instruments, and document management procedures for increasing legal protection, instead of improving the organisation's performance (Vommaro, 2017).

When you go beyond the mere document management procedures, inspired by the principle of defensive administration that goes at a pace with and adds up to defensive medicine, the typical approach is investigating and finding broken-up best practices for some of the components of the therapeutic procedure or for specific areas of risk management. In most cases, compliance is reasonably good in one or more items of the selected best practice, but reliability and consistency dramatically drop when you look at the process as a whole (Palumbo, 2017b). Even if the entire therapeutic procedure described by the literature could be fully implemented with the help of national and international scientific associations, it would hardly ever be set in the context of its specific scope of application, with ICT tools developed to make the requisite interconnections between different clinicalmedical IT systems and to investigate the criticalities and potential innovative connections between all assets and parties involved in the production of health as a value. However, costs and results are never assessed from an integrated perspective (Bowling, 2014; Manolitzas et al., 2016).

To trigger a beneficial process that effectively and sustainably pursues the problem of health expenditure within a regional healthcare system, an integrated approach focussed on the production of value must be taken (Bauchner et al., 2016; Zejnilović et al., 2016).

Here, we propose a model called T.R.E.E., which has been designed for some healthcare facilities in Campania (Southern Italy), aimed to trigger a learning process, so that all players can thoroughly investigate the patient-treating process in different medical conditions, to find (with the help of benchmarking techniques) the best possible organisation (with the best combination of resources) for each one, and lastly to measure and report the production of value.

T.R.E.E. stands for the different steps of the project, which may be summed up as Training, Reengineering, Evaluating (costs, risks, results) and, lastly, Exhibiting (the final results).

The first step, Training, aims at creating a common ground for the players involved in the organisation's mission, providing them with all the tools they may need to produce the highest possible value in relation to the vision, mission and goals (which may be slightly adjusted). From this perspective, training lays the ground to increase "transparency" in healthcare organisations: this happens with their own staff, who can openly and quickly share information through a common language, as well as with other stakeholders, who can interact with a cohesive, integrated system of players.

The Reorganisation step involves reengineering processes that are consistent with the vision, mission and goals, which, in healthcare, basically consists in finding organisational solutions that try to integrate healthcare services, so as to maximise the production of health as a value. 'Re-' means that this effort is complicated by the fact it happens within an existing organisation, which has its own background, its routines and its balance. We like to think of a healthcare facility as of a flying airplane that never stops. Reorganisation efforts must not only make the most of the contribution of all the available resources for the success of the therapeutic path, 
but they must also make it happen without the airplane falling down, that is, without impairing the organisation's daily operation, in a perfect balance of routine and innovation.

Then, the value created by the on-going organisational change process must be disclosed - as clearly as possible. This is the purpose of the Evaluation step, which aims at further expanding the healthcare facility's transparency by measuring the value produced by a systemic redefinition of the organisational practices. In other words, this is about curbing causal ambiguity and making the most of the benefits provided by the implementation of the project in relation to the organisation's mission. This minimises the risk that the organisations involved in the implementation of the project may show some resistance to the change process, mainly because they feel the need to protect their own organisational autonomy.

The circle is closed by the Exhibiting step, which is both the start and the end. On one hand, it summarises the progress of the project by showing the value produced in relation to the organisation's mission; on the other hand, through the overwhelming scope of transparency, it helps wake up other 'sleeping' assets, to make the project spread like wildfire.

A distinctive feature of this model is that there is no specific step in the project in which the mission, purposes and goals are defined or redefined. This does not mean that the purposive approach has been disregarded, as it is actually the key drive which makes sense of every action, but it means that we did not want to separate such moment, we wanted instead to make it 'immanent' in every step: the Training step is triggered by the mission and goals, and then it goes back to them as it shapes the models and tools that are thought; adjusting the mission or improving its operational goals may be an outcome of the training process that can come out of classroom interaction. Likewise, the Reorganising step is a function of the mission and goals, and gives them cues; the Evaluating step tries to show the value of production in relation to the mission and goals, i.e. the desired value; lastly, the Exhibiting step aims at communicating the value produced in relation to the mission, as originally worked out or as readjusted across the whole change management cycle.

For the ease of presentation, the four steps have been described in a sequence, but in practice they have mixed dynamics (sequential, contextual) in the typical iterative-recursive form of a 'try and learn' process.

The T.R.E.E. model combines the strengths of the three approaches to organisational change ('top-down', 'outside-in' and 'inside-up'), while making the most of the need for transparency and spending review.

The 'outside-in' factor can be found in the remarkable contribution made by the university through its II-level Master's programme in Healthcare leadership and management (DAOSan). Such master's programme is based on action learning, whereby professionals learn and are made aware through effective learner-centred methods, which allow for upgrading the qualifications of the human resources involved in the healthcare system, and remarkably reducing the costs of consultation and updating

The 'top-down' factor can be found in the involvement of multiple institutional stakeholders, not only the healthcare facility's top management but also the regional boards that have verbally agreed to join the project, in support of the academicians' efforts. In this way, one can aspire to far-ranging results, such as 
building a regional databank of clinical risks, costs and results, interconnected with similar national and international databanks.

The project also includes a 'bottom-up' approach: each initiative is the result of joint efforts with the partners of the university master's programme. While, on one hand, through the master's programme, the academic community sets a suitable context for inter-institutional and inter-professional interaction and sharing, on the other hand the processes that must be acted upon are selected in consultation with the organisations which are partners of the Master's programme.

The metaphor of the tree is enlightening to set the project in the right context. Instead of the top, imagine a trunk with the branches embedded in it, then growing and developing into leaves and fruit. Each branch is a value-producing process (the flowers and the fruit). The tree lives because it is rooted into the ground (the cultural substratum). Its energy stems from its deep, hidden roots: the root is what enables the tree to bear fruit by delving deep into something wide - the ground from which it takes its nourishment. Nourishment can come from below (the roots) or from interaction with the environment, above all photosynthesis in the leaves. The fruit is the concentration of the energy of the life-giving sap that runs through the tree, the accomplishment whereby a seed can be planted in the ground to start a new cycle all over again. The fruit and the leaves, by falling down, help produce the nourishment that is soaked up through the roots. They are given back to the ground underneath the tree, as well as into the surrounding soil.

Here, the analogies with the project are intuitive; the purpose is to emphasise the importance of the context as an essential cultural substratum for the development of the project. It includes a value factor and a technical-scientific factor, consisting of the key models and theoretical aids developed at the Training stage, namely:

- Innovative learner-centred training models, based on the latest scientific findings about effective adult-learning programmes (action learning, problembased learning, appreciative enquiry), where classroom and on-site training may be alternated and students can be taken through an experiential learning cycle, which in turn helps promote change as well as professional and organisational development.

- Innovative tools for the analysis and formal modelling of social-healthcare processes that can be used to map integrated paths (including interorganisational ones) and that are flexible enough to accommodate prevalent scientific standards as well as local and facility-specific variables associated with the patients, in a complex perspective in which all players (including patients and their families, as well as suppliers) are part of a process for the cocreation of health as a value. Such tools are built on easy-to-use, adaptable standards and are consistent with the national and European guidelines on interoperability (Smart Open Services for European Patients);

- Value-estimation models, whereby value is measured as a difference between the clinical outcome (with inbuilt risks) and the cost, from a patient-based perspective. More to the point, outcome-evaluation models that factor in the risks and use algorithms from other disciplines, based on reliability science principles and adapted to the specific context of healthcare, as well as Activitybased cost-evaluation models, instead of traditional 'top-down' cost-evaluation models; 
- Models of communication that apply as much within the organisation itself as outside it. Within the organisation, they can be used to: 1) support with the choice of an optimal process based on measureable cost, risk and result indicators, 2) monitor diagnostic-therapeutic paths by tracking compliance with protocols and delivering real-time feedback about deviations and potential alternative options, including guidance about cost/risk/result indicators, 3) improve the participants' self-confidence and intrinsic motivation. Externally, they may be used to: 1) facilitate sharing of knowledge between different public sector organisations, 2) raise the users/citizens' awareness, 3) establish a benchmark that, if properly replicated on a regional and/or national scale, can be an effective response to the healthcare policies and guidelines.

\section{Conclusions and Emerging Issues}

Transparency and spending reviews have often been presented as pipedreams rather than as attainable targets in the public sector (Heald, 2012). It is not surprising then that the lawmaker - in most cases - opted for a 'top-down' approach to trigger a change of organisational policies, in keeping with the need for administrative transparency and managerial efficiency in the public sector (Luingholm, 2015). The adoption of a sort of command\&control 'top-down' approach has been - partly - legitimised as an attempt to make the enforcement of transparency criteria in public companies and organisations as fast and straightforward as possible; nevertheless, it prevented the intellectual and social capital of each company from settling so that transparency could become a guiding principle for the organisational work (Bouckaert et al., 2015).

It is too soon to assess the effectiveness of the T.R.E.E. model, which is still in its first Training stage. It is certainly an innovative model, which combines a 'topdown' framework with 'outside-in' and 'inside-up' approaches. On one side, it involves third parties - such as universities - that, as consultants, carry energies that are essential to promote and boost change in the public sector; on the other side, it makes the most of the resilience of each public sector organisation and its ability to take ad-hoc initiatives to respond to the transparency and spending reviews that are laid down by the institutions. This will sidestep the risk that transparency may be - aseptically - regarded as a remedy for all diseases (De Vries $\&$ Sobis, 2016). The ability to create a systemic vision and a network-like attitude within the public sector should make transparency and spending review an attainable goal instead of an unrealistic policy.

Note the fractal element of the tree and the T.R.E.E. project, i.e. the fact that every part of the Training, Reorganizing, Evaluating, Exhibiting cycle contains the entire cycle.

For instance, the Training step is, in turn, divided into four steps that reproduce the T.R.E.E. cycle:

Training: development of learning in the participating public sector organisations, while building a cohesive cross-cutting community of practice who share the same vision and mission, who can independently implement the model and generate results so as to reach a critical mass for change, reduce dependency on third parties, and boost further innovation; 
Reorganizing: developing the ability to reorganise the available resources (human, instrumental, structural, financial and intangible), including any 'sleeping' or unexploited one, so that all of them can be made the most of and placed synergistically to the mission, thus building appropriate therapeutic and healthcare processes that do respond to the patients' need for healthcare;

Evaluating: developing the ability to conduct regular assessments of the progress of the project through an integrated, inter-disciplinary and cooperative approach, whereby the production of value can be established in relation to the mission, in terms of difference between clinical outcomes, risks and costs from a patient-based perspective;

Exhibiting: developing the ability to communicate the results and make them transparent, in the attempt to support the organisation's own decision-making process and ease the sharing of knowledge between public sector organisations, as well as the ability to scale the results to regional and national levels, thus remarkably innovating the healthcare system.

Similarly, the Reorganising stage is spread over each one of the four steps (Training, Reorganizing, Evaluating, Exhibiting): all of them must be organised so as to maximise the production of value. Likewise, all four steps must be evaluated so as to measure the value produced, and all four must be communicated and made transparent in terms of value produced.

The fractal element can also be found in the dynamic development of the project. It starts with a few pilot processes, then branches off into other processes, just like a tree that puts out branches, still applying the T.R.E.E. cycle in a recursive pattern. T.R.E.E. should be regarded as a process itself, in which players and assets are brought together in the best possible combination to offer the greatest value to all stakeholders. The University lecturers' skills are used not only to provide abstract knowledge but to do something useful for the local players; the healthcare facilities' skills are exploited by training programmes and instantly turned into applicative skills; the healthcare facilities' wealth of data and information is made available to support allocation policies and management choices, and as a basis for the advancement of knowledge. Players can personally experience the T.R.E.E. cycle in an endless reorganisation and evaluation of costs/results from an experimental perspective, constantly focussed on correcting and updating the knowledge produced. What is important is not the success of each action or action plan, but the unfailing effort to re-contextualise the organisational and managerial innovation around the new emerging issues. In insisting, the players test their abilities and put learning processes into practice. Without such "smart insistence", any attempt at making healthcare truly transparent is bound to fail and the spending review to remain what it has been so far: a pipedream.

\section{Acknowledgment}

I would like to thank Dr. Rocco Palumbo, a brilliant Research Fellow in Organization Studies, University of Salerno, for his valuable contribution to this paper, particularly to the bibliographical research. 


\section{Bibliography}

Acra, A., Jurdi, M., Mu'allem, H., Karahagopian, Y., \& Raffoul, Z. (1989). Sunlight as disinfectant. Lancet, 333 (8632), 280-281. http://dx.doi.org/10.1016/S0140-6736(89)91293-2

Barth, J. R., Lin, C., Lin, P., \& Song, F. M. (2009). Corruption in bank lending to firms: Crosscountry micro evidence on the beneficial role of competition and information sharing. Journal of Financial Economics , 91 (3), 361-388.

http://dx.doi.org/0.1016/j.jfineco.2008.04.003

Bauchner, H., Berwick, D., \& Fontanarosa, P. B. (2016). Innovations in Health Care Delivery and the Future of Medicine. JAMA , 315 (1), 30-31.

http://dx.doi.org/10.1001/jama.2015.17452

Bisio, L. (2006). Public Governance and Financial Communication. Symphonya. Emerging Issues in Management (symphonya.unimib.it), 1, 110-128.

http://dx.doi.org/10.4468/2006.1.08bisio

Bowling, A. (2014). Research Methods In Health: Investigating Health And Health Services. New York: Open University Press.

Brondoni, S. M. (2016). Global Tourism and Terrorism. Safety and Security Management. Symphonya. Emerging Issues in Management (symphonya.unimib.it), 2, 7-16.

http://dx.doi.org/0.4468/2016.2.02brondoni.

Codignola, F. (2003). The Art Market, Global Economy and Information Transparency. Symphonya. Emerging Issues in Management (symphonya.unimib.it) 73-93.

http://dx.doi.org/10.4468/2003.2.07codignola.

Cucciniello, M., Porumbescu, G. A., \& Grimmelikhuisen, S. (2017). 25 Years of Transparency Research: Evidence and Future Directions. Public Administration Review , 77 (1), 32-44. http://dx.doi.org/10.1111/puar.12685.

De Leonardis, F. (2016). Tra obblighi di trasparenza e diritto alla riservatezza: verso una trasparenza di tipo "funzionale". Giornale di Storia Costituzionale , 31, 175-184.

Fadda, I., \& Paglietti, P. (2016). La lotta alla corruzione: più controlli interni e meno adempimenti. Azienda Pubblica , 29 (1), 81-96.

Fei, K., \& Vlasses, F. R. (2008). Creating a Safety Culture Through the Application of Reliability Science. Journal for Healthcare Quality , 6, 37-43.

http://dx.doi.org/10.1111/j.1945-1474.2008.tb01168.x/full

Frumkin, P., \& Galaskiewicz, J. (2004). Institutional Isomorphism and Public Sector Organizations. Journal of Public Administration Research and Theory, 14 (3), 283-307.

http://dx.doi.org/10.1093/jopart/muh028.

Gorodnichenko, Y., \& Peter, K. S. (2007). Public sector pay and corruption: Measuring bribery from micro data. Journal of Public Economics , 5-6, 963-991.

http://dx.doi.org/10.1016/j.jpubeco.2006.12.003.

Hameroff, S. R. (1998). Did Consciousness Cause the Cambrian Evolutionary Explosion? In S. R. Hameroff, A. W. Kaszniak, \& A. Scott, Toward a Science of Consciousness II: The Second Tucson Discussion and Debates (p. 421-438). Cambridge, MA: MIT Press.

Hellwig, C. (2002). Public Information, Private Information, and the Multiplicity of Equilibria in Coordination Games. Journal of Economic Theory, 107 (2), 191-222.

http://dx.doi.org/ 10.1006/jeth.2002.2947.

Hirschman, A. (1981). The Rise and Decline of Development Economics in Essays in Trespassing." Economics to politics and beyond. Cambridge: Cambridge University Press.

Hyndman, N., Liguori, M., Meyer, R. E., Polzer, T., Rota, S., Seiwald, J., et al. (2017). Legitimating change in the public sector: the introduction of (rational?) accounting practices in the United Kingdom, Italy and Austria. Public Administration Review, Published on-line ahead of print on October, 12th 2017. 
http://dx.doi.org/10.1080/14719037.2017.1383781

IOM. (2000). To Err Is Human: Building A Safer Health System. Washington, DC: National Academies Press.

Janssen, M., Konopnicki, D., Snowdon, J. L., \& Ojo, A. (2017). Driving public sector innovation using big and open linked data (BOLD). Information Systems Frontiers, 19 (2), 189-195. http://dx.doi.org/10.1007/s10796-017-9746-2.

Janssen, M., Matheus, R., Longo, J., \& Weerakkody, V. (2017). Transparency-by-design as a foundation for open government. Transforming Government: People, Process and Policy, 11 (1), 2-8. http://dx.doi.org/10.1108/TG-02-2017-0015.

Kruse, C. S., Frederick, B., Jacobson, T., \& Monticone, D. K. (2017). Cybersecurity in healthcare: A systematic review of modern threats and trends. Technology and Health Care , 25 (1), 1-10.

Lenk, K. (2002). Electronic Service Delivery - A driver of public sector modernisation. Information Polity , 7 (2-3), 87-96.

Leydesdorff, L., \& Zhou, P. (2014). Measuring the knowledge-based economy of China in terms of synergy among technological, organizational, and geographic attributes of firms. Scientometric , 98 (3), 1703-1719.

http://dx.doi.org/0.1007/s11192-013-1179-1

Loveday, H., Wilson, J., Pratt, R., Golsorkhi, M., Tingle, A., Bak, A., et al. (2013). epic3: National Evidence-Based Guidelines for Preventing Healthcare-Associated Infections in NHS Hospitals in England. Journal of Hospital Infection , 1-70.

http://dx.doi.org/10.1016/S0195-6701(13)60012-2.

Makary, M. A., \& Daniel, M. (2016). Medical error-the third leading cause of death in the US. British Medical Journal, http://dx.doi.org/10.1136/bmj.i2139.

Manolitzas, P., Grigoroudis, E., Matsatsinis, N., \& Yannacopoulos, D. (2016). Effective Methods for Modern Healthcare Service Quality and Evaluation. Hershey, PA: IGI Global.

Moullin, M. (2017). Improving and evaluating performance with the Public Sector Scorecard. International Journal of Productivity and Performance Management , 66 (4), 442-458. http://dx.doi.org/10.1108/IJPPM-06-2015-0092.

Palumbo, R. (2016). Contextualizing co-production of health care: a systematic literature review. International Journal of Public Sector Management , 29 (1), 72-90. http://dx.doi.org/10.1108/IJPSM-07-2015-0125.

Patey, R., Flin, R., Cuthbertson, B. H., MacDonald, L., Mearns, K., Cleland, J., et al. (2007). Patient safety: helping medical students understand error in healthcare. BMJ Quality \& Safety, 16 (4), http://dx.doi.org/10.1136/qshc.2006.021014.

Perroux, F. (1983). A New Concept of Development: Basic Tenets. Abingdon, OX: Routledge.

Raisch, S., \& Birkinshaw, J. (2008). Organizational Ambidexterity: Antecedents, Outcomes, and Moderators. Journal of Management , 34 (3), 375-409.

http://dx.doi.org/10.1177/0149206308316058.

Roberts, J. G., Henderson, J. G., Olive, L. A., \& Obaka, D. (2013). A Review of Outsourcing of Services in Health Care Organizations. Journal of Outsourcing and Organizational Information Management , 1, 1-10.

Salvioni, D. M. (2002). Transparency Culture and Financial Communication. Symphonya. Emerging Issues in Management (symphonya.unimib.it), 2, 22-33.

http://dx.doi.org/10.4468/2002.2.04salvioni

Schlegelmilch, B. B., Ambos, B., \& Chini, T. C. (2003). Are You Ready to Learn from Your Offshore Affiliates? Symphonya. Emerging Issues in Management (symphonya.unimib.it), 2, 2733.

http://dx.doi.org/10.4468/2003.2.03schlegelmich.ambos.chini

Shergold, P. (2017). Re-imagining public service. Australian Journal of Social Issues , 52 (1), 4-12. http://dx.doi.org/10.1002/ajs4.7. 
Strang, D., \& Macy, M. W. (2001). In Search of Excellence: Fads, Success Stories, and Adaptive Emulation. American Journal of Sociology, 107 (1), 147-182. DOI: 10.1086/323039.

Taylor, R., \& Kelsey, T. (2016). Review of Transparency and the Open Society: Practical Lessons for Effective Policy. Bristol, UK: Policy Press.

Themudo, N. S. (2014). Government Size, Nonprofit Sector Strength, and Corruption. A CrossNational Examination. The American Review of Public Administration , 44 (3), 309-323. http://dx.doi.org/10.1177/0275074012465791.

Valentine, J., Jablonski, D., \& Erwin, D. (1999). Fossils, molecules and embryos: new perspectives on the Cambrian explosion. Development, 126, 851-859.

Vommaro, A. (2017). Dal Risk Management Al Performance Management Gli Effetti Economici Della Minimizzazione Dell'errore In Terapia. Economia Aziendale On-Line , 8 (1), 1-7.

http://dx.doi.org/ 10.13132/2038-5498/8.1.1-7.

WHO. (2011). Report on the Burden of Endemic Health Care-Associated Infection Worldwide. Clean Care is Safer Care. Geneva: WHO Document Production Services.

Woolf, S. H., Kuzel, A. J., Dovey, S. M., \& Phillips Jr, R. L. (2004). A String of Mistakes: The Importance of Cascade Analysis in Describing, Counting, and Preventing Medical Errors. Annals of Family Medicine , 2 (4), 317-326.

http://dx.doi.org/10.1370/afm.126

Zejnilović, L., Oliveira, P., \& Canhão, H. (2016). Innovations by and for Patients, and Their Place in the Future Health Care System. In H. Albach, H. Meffert, A. Pinkwart, R. Reichwald, \& W. von Eiff, Boundarlyless Hospital (p. 341-357). Berlin: Springer.

Zimlichman, E., Henderson, D., Tamir, O., Franz, C., Song, P., Yamin, C. K., et al. (2013). Health Care-Associated InfectionsA Meta-analysis of Costs and Financial Impact on the US Health Care System. JAMA Internal Medicine , 173 (22), 2039-2046.

http://dx.doi.org/10.1001/jamainternmed.2013.9763 